\title{
Transcriptome Profiling of Human Follicle Dermal Papilla Cells in response to Porphyra-334 Treatment by RNA-Seq
}

\author{
Su Yeon Kim, ${ }^{1,2}$ Won Kyong Cho $\mathbb{D}^{3}{ }^{3}$ Hye-In Kim, ${ }^{2}$ Seung Hye Paek, ${ }^{2}$ Sung Joo Jang, \\ Yeonhwa Jo $\mathbb{D}{ }^{3}{ }^{3}$ Hoseong Choi $\mathbb{D}^{3},{ }^{3}$ Jeong Hun Lee, ${ }^{2}$ and Sang Hyun Moh $\mathbb{D}^{2}$ \\ ${ }^{1}$ Department of Bio Cosmetics, Sungkyunkwan University, Suwon 16419, Republic of Korea \\ ${ }^{2}$ Anti-aging Research Institute of BIO-FD\&C Co., Ltd., Incheon 21990, Republic of Korea \\ ${ }^{3}$ Research Institute of Agriculture and Life Sciences, College of Agriculture and Life Sciences, Seoul National University, \\ Seoul 08826, Republic of Korea \\ Correspondence should be addressed to Sang Hyun Moh; biofdnc@gmail.com
}

Received 6 November 2020; Revised 18 December 2020; Accepted 4 January 2021; Published 13 January 2021

Academic Editor: Jiangquan Liao

Copyright ( 2021 Su Yeon Kim et al. This is an open access article distributed under the Creative Commons Attribution License, which permits unrestricted use, distribution, and reproduction in any medium, provided the original work is properly cited.

Porphyra-334 is a kind of mycosporine-like amino acid absorbing ultraviolet-A. Here, we characterized porphyra-334 as a potential antiaging agent. An in vitro assay revealed that porphyra-334 dramatically promoted collagen synthesis in fibroblast cells. The effect of porphyra-334 on cell proliferation was dependent on the cell type, and the increase of cell viability by porphyra334 was the highest in keratinocyte cells among the three tested cell types. An in vivo clinical test with 22 participants demonstrated the possible role of porphyra-334 in the improvement of periorbital wrinkles. RNA-sequencing using human follicle dermal papilla (HFDP) cells upon porphyra-334 treatment identified the upregulation of metallothionein- (MT-) associated genes, confirming the antioxidant role of porphyra-334 with MT. Moreover, the expression of genes involved in nuclear chromosome segregation and the encoding of components of kinetochores was upregulated by porphyra-334 treatment. Furthermore, we found that several genes associated with the hair follicle cycle, the hair follicle structure, the epidermal structure, and stem cells were upregulated by porphyra-334 treatment, suggesting the potential role of porphyra-334 in hair follicle growth and maintenance. In summary, we provided several new pieces of evidence of porphyra-334 as a potential antiaging cosmetic agent and elucidated the expression network in HFDP cells upon porphyra-334.

\section{Introduction}

Mycosporine-like amino acids (MAAs) are small secondary metabolites that were first identified from fungi showing ultraviolet- (UV-) induced sporulation [1]. MAAs are commonly identified from a wide range of freshwater and marine organisms, such as cyanobacteria, marine algae, and seaweed $[2,3]$. To date, MAAs have been identified from 572 species of marine macroalgae [4]. In addition, some marine vertebrates and invertebrates, such as medaka fish, Antarctic krill, and scallops, acquire MAAs from dietary marine algae [5-7]. MAAs are low-molecular-weight (generally less than $400 \mathrm{Da}$ ) and water-soluble molecules that can absorb UV radiation (UVR). MAAs consist of a cyclohexenimine ring conjugated with two amino acid substituents [8].
MAAs can protect cells from solar UVR by absorbing UVR typically between 310 and $340 \mathrm{~nm}$ [9]. Moreover, MAAs have diverse functions, including protection from free-radical damage and resistance to several stresses, such as hypersalinity, desiccation, and heat stress $[2,10]$. To date, the chemical structures of more than 30 different MAAs as natural metabolites have been revealed [11]. In microalgae, the six most abundant components of MAAs were found to be palythene, palythine, mycosporine-glycine, palythenic acid, porphyra-334, and shinorine [3].

Porphyra-334, a kind of MAA, is a potential natural metabolite that can protect against UVA $[12,13]$ and has antioxidant activity $[14,15]$. Porphyra-334 was initially identified from the red alga, Porphyra tenera Kjellman, and its amino acid structure was determined in 1979 [16]. 
Since then, porphyra-334 has been purified from diverse marine organisms, such as Bangia atropurpurea [17], Nostoc sphaericum [18], Porphyra vietnamensis [19], and Porphyra yezoensis [20]. Porphyra-334's protective effect against UVA has been examined in diverse human cells. For instance, porphyra-334 was shown to inhibit UVinduced apoptosis in human immortalized keratinocyte (HaCaT) cells by attenuation of the caspase pathway [21]. Porphyra-334 extracted from Porphyra yezoensis induced photoaging in human skin fibroblasts in response to UVA irradiation by suppressing reactive oxygen species (ROS) production and expression of nuclear factor $-\kappa \mathrm{B}(\mathrm{NF}-\kappa \mathrm{B})$ but activating the NF-E2-related factor 2 (Nrf2) signaling pathways $[20,22]$. A previous study conducted transcriptome analysis of human keratinocyte cells in the presence of porphyra-334 exposed to UVR using cDNA and miRNAs microarray [23]. Furthermore, our recent study demonstrated that porphyra-334 efficiently promotes cell reprogramming by activating both mesenchymal to epithelial transition (MET) and the trimethylation of histone 3 lysine 4 (H3K4me3) [24].

Although porphyra-334 has a wide range of functions, its potential role as a cosmetic material has not been well studied. In this study, we characterized porphyra-334 for the promotion of collagen synthesis by in vitro assay and for the reduction of periorbital wrinkling by in vivo clinical test. In addition, we established transcriptome profiling of human follicle dermal papilla (HFDP) cells in response to porphyra334 by RNA-seq to reveal the gene expression network associated with porphyra-334.

\section{Materials and Methods}

2.1. Preparation of Porphyra Extract and Porphyra-334. Porphyra yezoensis used in this study was purchased from a market. We obtained porphyra extract by heat extraction with $25 \mathrm{~kg}$ of Porphyra yezoensis, $988 \mathrm{~kg}$ of distilled water, $10 \mathrm{~kg}$ of butylene glycol, and $2 \mathrm{~kg}$ of 1,2 -Hexanediol at $40-50^{\circ} \mathrm{C}$ for $12 \mathrm{~h}$. Porphyra-334 was purified from the porphyra extract. The content of porphyra-334 in the porphyra extract was found to be $1000 \mathrm{ppm}$ based on HPLC analysis.

2.2. Cultivation of Human Cells. Three different types of human cells were used in this study: human Detroit 551 fibroblast cells (ATCC, Manassas, VA, USA), human immortalized keratinocyte (HaCaT) cells (ATCC), and HFDP cells derived from mainly normal human scalp hair follicles (ScienCell, San Diego, CA, USA). Detroit 551 and HaCaT cells were cultivated in Dulbecco's Modified Eagle Medium (DMEM) (Welgene, Gyeongsan-si, Korea) supplemented with 10\% Fetal Bovine Serum (FBS) (Thermo Fisher Scientific, Waltham, MA, USA) and penicillinstreptomycin $(10,000 \mathrm{U} / \mathrm{mL})$ (Thermo Fisher Scientific) at $37^{\circ} \mathrm{C}$ with a $5 \% \mathrm{CO}_{2}$ condition. We cultivated HFDP cells in mesenchymal stem cell medium-basal (MSCM-b) (ScienCell) including $10 \% \mathrm{FBS}$ and $1 \mathrm{X}$ Antibiotics at $37^{\circ} \mathrm{C}$ in $5 \%$ $\mathrm{CO}_{2}$.
2.3. Evaluation of Cell Metabolic Activity by MTT Assay. We conducted an MTT (3-(4,5-dimethylthiazol-2-yl)2,5-diphenyltetrazolium bromide) assay to measure the effect of porphyra extract and porphyra-334 on the cell viability, proliferation, and cytotoxicity of the three different human cells (Detroit 551, HaCaT, and HFDP cells). We treated Detroit 551 cells with three different concentrations $(1,5$, and $10 \mathrm{ppm})$ of porphyra extract and porphyra-334. HaCaT and HFDP cells were both treated with six different concentrations of porphyra-334 (1, 5, $10,50,100$, and $200 \mathrm{ppm})$. Distilled water was used as a control. We incubated Detroit 551, HaCaT, and HFDP cells at a density of $5 \times 10^{4}$ cells per well in a 96 -well plate for $24 \mathrm{~h}$. Individual cells were treated with different concentrations of porphyra extract, porphyra-334, and distilled water. After $24 \mathrm{~h}$ of treatment, the medium was removed, $4 \mu \mathrm{L}$ of $5 \mathrm{mg} / \mathrm{mL}$ MTT (Sigma-Aldrich, St. Louis, MO, USA) was added, and they were incubated for $4 \mathrm{~h}$. We again removed the medium, added $100 \mu \mathrm{L}$ of dimethylsulfoxide (DMSO) (Sigma), and let it dissolve for $10 \mathrm{~min}$. We measured the wavelength absorbance at $570 \mathrm{~nm}$ using a Thermo Scientific Multiskan GO Microplate Spectrophotometer (Fisher Scientific Ltd., Vantaa, Finland). Cell viability was calculated using the following formula: cell viability $(\%)=($ amount of $a b-$ sorbance of treated cells/amount of absorbance of control cells) $\times 100$.

2.4. Measurement of Collagen Synthesis. To measure the improvement in collagen synthesis by porphyra extract and porphyra-334, we determined procollagen expression levels using the Procollagen Type I C-Peptide (PIP) EIA kit according to the manufacturer's instructions (Takara Korea Biomedical Inc., Seoul, Korea).

\subsection{Clinical Evaluation of Efficacy of Cream Containing} Porphyra-334 for Improvement of Periorbital Wrinkles. The clinical study for the evaluation of the efficacy of a cream containing porphyra-334 (10 ppm) for the improvement of periorbital wrinkles was carried out by the Skin Research Center (Seoul, Korea) after approval was obtained based on the standard operating procedures of the Skin Research Center IRB. The research proposal (KC-IRB-31) was submitted on September 10, 2019, and accepted on October 05, 2019. All clinical evaluations were carried out according to the guideline for Good Clinical Practice (GCP) by the International Conference on Harmonization.

We selected a total of 23 healthy female volunteers (30 to 65 years old) showing periorbital wrinkles. The test product (porphyra-334) was a cream containing porphyra-334 (10 ppm), and the control product was a cream without porphyra-334. All volunteers applied the test and control products to the eye area after washing their face. The treatment was randomly conducted on the left or right side of volunteers' faces. Our test was a double-blind test in which neither the subjects nor the researchers knew which product was a test sample. The treatment was conducted in the morning and in the evening for 12 weeks. We examined skin 
and took photographs at three different time points: baseline before use, after 6 weeks, and after 12 weeks. Periorbital wrinkles were measured by a Skin Visiometer SV700 (Courage and Khazaka, Köln, Germany). The images of individual volunteers' periorbital wrinkles were taken using Mark-Vu (PSI Plus, Suwon, Korea). The evaluations of periorbital wrinkling were conducted using three different methods. The first was the measurement of periorbital wrinkles by a Skin Visiometer SV700 based on periorbital wrinkling parameters: R1 (skin roughness), R2 (maximum roughness), R3 (average roughness), R4 (smoothness depth), and R5 (arithmetic average roughness). The second was a self-assessment by volunteers in which the participants filled out questionnaires on their global assessment of the efficacy and their subjective satisfaction. The third was a visual assessment by two dermatologists.

2.6. RNA Extraction, Library Preparation, and Next-Generation Sequencing. To establish a transcriptome profile of HFDP cells in response to porphyra-334 treatment, HFDP cells at a density of $1 \times 10^{6}$ cells per well were incubated in a six-well plate for $24 \mathrm{~h}$. Next, we treated HFDP cells with $10 \mathrm{ppm}$ of porphyra-334 (treatment) or distilled water (control) for $24 \mathrm{~h}$. We harvested three different biological replicates for each condition. We extracted total RNA using an RNeasy Mini Kit (Qiagen, Hilden, Germany) according to the manufacturer's instructions. The extracted total RNAs were used for mRNA library preparation using the TruSeq Stranded mRNA LT Sample Prep Kit according to the manufacturer's instructions. We generated six different libraries from two different conditions with three biological replicates. The six libraries were paired-end sequenced by Illumina's NovaSeq 6000 system (Macrogen, Seoul, Korea). We deposited the obtained raw sequence data in the National Center for Biotechnology Information (NCBI) Sequence Read Archive (SRA) database with the following respective accession numbers: SRR12641544-SRR12641549.

2.7. Transcriptome Analysis and Gene Ontology Term Enrichment Analysis. Raw sequence reads from each library were trimmed using the PRINSEQ program with a quality score of 20 [25]. Next, clean reads were mapped on the human reference transcripts version GRCh38 (https://www. ncbi.nlm.nih.gov/genome/guide/human/) using the BWA with default parameters (http://bio-bwa.sourceforge.net/) resulting in SAM file format. The SAM files containing mapping information were subjected to the eXpress program (https://pachterlab.github.io/eXpress/manual.html) to calculate the number of reads mapped on individual human transcripts. The comma-separated values (CSV format) containing the number of reads for individual human transcripts were obtained using the GENAVi (https:// junkdnalab.shinyapps.io/GENAVi/) program. Normalization was conducted using the DESeq2 package implemented in GENAVi. Differentially expressed genes (DEGs) between treatment and control conditions were identified based on adjusted $p$ values of less than 0.01 and $\log 2$ converted fold changes of more than 1 .
To identify enriched functions in the identified DEGs, we conducted gene ontology (GO) term enrichment analysis using the WEB-based Gene SeT AnaLysis Toolkit (WebGestalt) (http://www.webgestalt.org/) [26]. The identified DEGs were divided into two groups: upregulated genes (39 transcripts) and downregulated genes (43 transcripts). The gene list in each group was subjected to overrepresentation analysis against the GO, KEGG, Panther, Reactome, WikiPathways, and WikiPathways Cancer databases with FDR 0.05 as a cutoff. The overrepresented GO terms were visualized by the directed acyclic graph (DAG) structure according to three categories: biological process (BP), cellular component (CC), and molecular function (MF).

2.8. Statistical Analysis. We conducted a one-way ANOVA test to compare the control and test samples. The results are shown as mean and standard deviation (mean \pm SEM). The $p$ values $p<0.05^{(*)}, p<0.01^{\left({ }^{* *}\right)}$, and $p<0.001^{\left({ }^{* *}\right)}$ were considered statistically significant. For the clinical evaluation of periorbital wrinkling, we conducted two different statistical analyses: paired samples $t$-test and independent $t$-test. $p$ values for $t$-test comparisons with baseline values are as follows: ${ }^{*}$ indicates $p<0.05,{ }^{* *}$ indicates $p<0.01$, and ${ }^{* * *}$ indicates $p<0.001$. * $p$ values for $t$-test comparisons between values in the test group and the control group are as follows: ${ }^{\#}$ indicates $p<0.05$. In the case of R5 and visual assessment, statistical analyses were carried out as follows: $\dagger$ indicates $p<0.05$ by Wilcoxon signed ranks test; ${ }^{*}$ indicates $p<0.05$ by paired samples $t$-test; ${ }^{\ddagger}$ indicates $p<0.05$ by Mann-Whitney $U$ test; ${ }^{\dagger}$ indicates $p$ values for $t$-test comparisons between values in the test group and the control group; ${ }^{\dagger}$ indicates $p<0.05 ;{ }^{\dagger \dagger}$ indicates $p<0.01$. All statistical tests were declared statistically significant at the 0.05 level. We used IBM SPSS Statistics version 21.0 (SPSS, Chicago, IL, USA) for the statistical analysis.

\section{Results}

3.1. Evaluation of Cell Viability and Collagen Formation by Porphyra Extract and Porphyra-334 in Detroit 551 Cells. We examined the effect of porphyra extract derived from Porphyra yezoensis and porphyra-334 on the cell viability and proliferation of Detroit 551 cells derived from human skin fibroblast cells. We used three different concentrations $(1,5$, and $10 \mathrm{ppm})$ of both porphyra extract and porphyra334. Cell viability was slightly increased after the application of 1 and $10 \mathrm{ppm}$ of both porphyra extract and porphyra-334; however, the application of 5 ppm of porphyra extract and porphyra-334 resulted in a slight reduction of viability (Figure 1(a)). The MTT assays showed that the application of 1 and 10 ppm of porphyra extract and porphyra-334 resulted in no cellular toxicity in Detroit 551 cells.

3.2. Evaluation of Collagen Formation by Porphyra Extract and Porphyra-334 in Detroit 551 Cells. We measured the effect of porphyra extract and porphyra-334 on collagen formation ability in Detroit 551 cells (Figure 1(b)). Again, Detroit 551 cells were treated with three different 


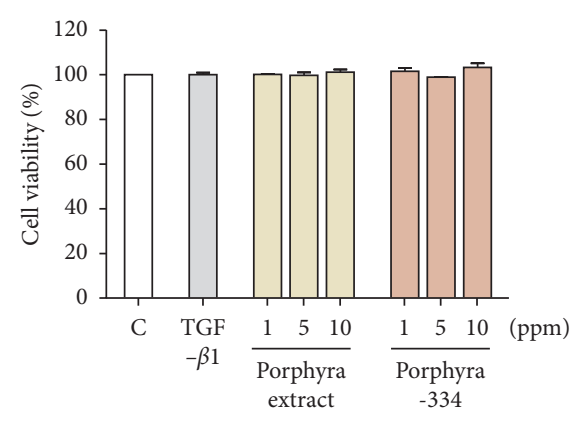

(a)

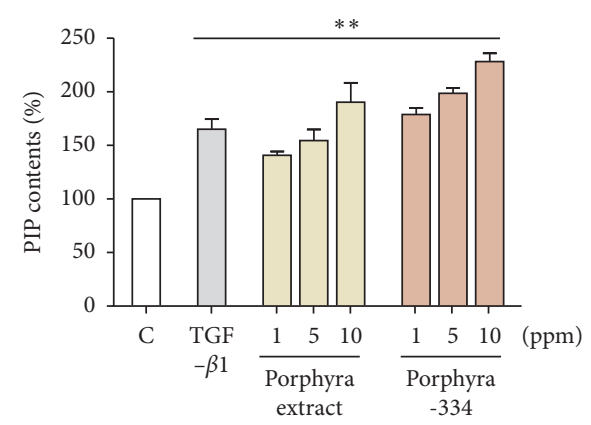

(b)

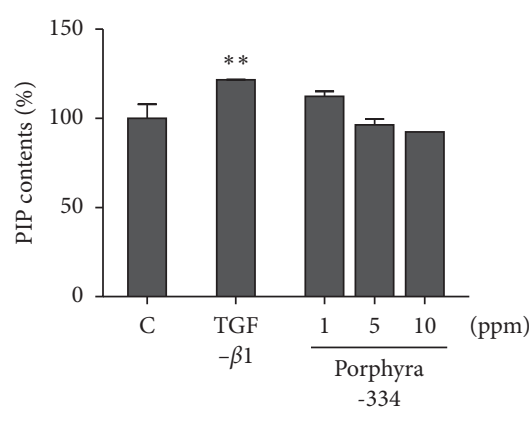

(c)

FIGURE 1: In vitro assessment of the effect of different concentrations of porphyra extract and porphyra-334 on cell viability and collagen synthesis. The effect of three different concentrations $(1,5$, and $10 \mathrm{ppm})$ of porphyra extract and porphyra-334 on the cell viability of Detroit 551 cells was examined by MTT assay (a). C indicates control cells treated with distilled water. (b) PIP content was measured in Detroit 551 cells after treatment with different concentrations of porphyra extract and porphyra-334. TGF- $\beta 1$, which is known to promote collagen formation, cell proliferation, and the differentiation of dermal fibroblasts, was used as a positive control. (c) PIP content was measured in HFDP cells after treatment with different concentrations of porphyra-334. For the comparisons between the positive sample (TGF- $\beta 1$ ) and the treatment group, we conducted independent $t$-tests. ${ }^{* *} p<0.01$.

concentrations $(1,5$, and $10 \mathrm{ppm})$ of porphyra extract and porphyra-334. Transforming growth factor-beta 1 (TGF- $\beta 1$ ), which is known to promote collagen type 1 production, was used as a positive control [27]. As compared to the control (distilled water), PIP content was increased $144 \%$ by TGF- $\beta 1$ treatment (Figure 1(b)). After the application of porphyra extract and porphyra-334, PIP content was increased as the concentration of porphyra extract and porphyra-334 increased. For example, PIP content was increased by $121 \%$ and $130 \%$ after the application of $1 \mathrm{ppm}$ of porphyra extract and porphyra-334, respectively. PIP content was increased by $147 \%$ and $154 \%$ after the application of $10 \mathrm{ppm}$ of porphyra extract and porphyra-334, respectively. The application of $5 \mathrm{ppm}$ of porphyra extract and porphyra-334 resulted in similar PIP content to TGF- $\beta 1$. The statistical analysis demonstrated that both porphyra extract and porphyra-334 significantly promoted collagen synthesis $(p=0.01)$. Next, we examined PIP content in HFDP cells after treatment with three different concentrations $(1,5$, and $10 \mathrm{ppm}$ ) of porphyra-334 (Figure 1(c)). PIP content in HFDP cells was increased by $121 \%$ by TGF- $\beta 1(p=0.01)$. After the application of porphyra-334 in HFDP cells, PIP content was decreased as the concentration of porphyra-334 increased. For instance, PIP content in HFDP cells was increased $112 \%$ by the treatment of $1 \mathrm{ppm}$ porphyra-334. By contrast, PIP content in HFDP cells was decreased by 5 ppm (96\%) and $10 \mathrm{ppm}$ (92\%) of porphyra-334. In addition, we examined PIP content in $\mathrm{HaCaT}$ cells after treatment with different concentrations of porphyra-334. However, PIP was not expressed in $\mathrm{HaCaT}$ cells.

\subsection{Effect of Porphyra-334 on Cell Viability in HaCaT and} HFDP Cells. It is important to examine the effect of porphyra-334 on cell viability and proliferation in different human cell lines and to determine whether increasing the concentration of porphyra-334 affects cell viability and proliferation. For that, we examined the effect of six different concentrations (1-200 ppm) of porphyra-334 on cell viability in two different human cell lines: human keratinocyte (HaCaT) and HFDP cells (Figures 2(a) and 2(b)). As compared to the control treated with distilled water, the MTT assay showed that the cell viability of the HaCaT cells increased as the concentration of porphyra-334 increased (Figure 2(a)). For example, the application of $1 \mathrm{ppm}$ of porphyra-334 resulted in $110.33 \%$ cell viability, while $200 \mathrm{ppm}$ of porphyra-334 resulted in $126.68 \%$ cell viability. The statistical analyses support that all six concentrations of porphyra-334 increased cell viability as compared to the control. In the case of HFDP, the treatment of HFDP cells with porphyra-334 resulted in an increase of cell viability (101.79\% (1 ppm) to $110.26 \%(200 \mathrm{ppm}))$ as compared to the control (Figure 2(b)). In particular, $10 \mathrm{ppm}(p=0.001)$, $50 \mathrm{ppm} \quad(p=0.01), 100 \mathrm{ppm} \quad(p=0.01)$, and $200 \mathrm{ppm}$ $(p=0.001)$ of porphyra-334 increased the cell viability of HFDP cells. However, the increase of cell viability by porphyra-334 in $\mathrm{HaCaT}$ cells was much higher than that in HFDP cells.

3.4. Clinical Evaluation of Porphyra-334 for Reduction of Periorbital Wrinkling. Next, we examined the possible efficacy of porphyra-334 for the reduction of periorbital wrinkling. For that, we prepared a test product (cream containing $10 \mathrm{ppm}$ of porphyra-334) and a control product (cream without porphyra-334). A total of 23 healthy female participants showing periorbital wrinkles were treated with test and control products. Using a Skin Visiometer SV700, we measured periorbital wrinkling according to five parameters: R1 (skin roughness), R2 (maximum roughness), R3 (average roughness), R4 (smoothness depth), and R5 (arithmetic average roughness). In R3 (average roughness), the periorbital wrinkling in the test group was significantly lower at 6 weeks $(p<0.001)$ and 12 weeks $(p<0.001)$ than at baseline (Table 1 and Figure 3(a)). The reduction of periorbital wrinkling was 1.85 times higher at 12 weeks $(-12.798 \%)$ as compared to 6 weeks $(-6.885 \%)$. We did not see any difference at 6 weeks or 12 weeks as compared to 


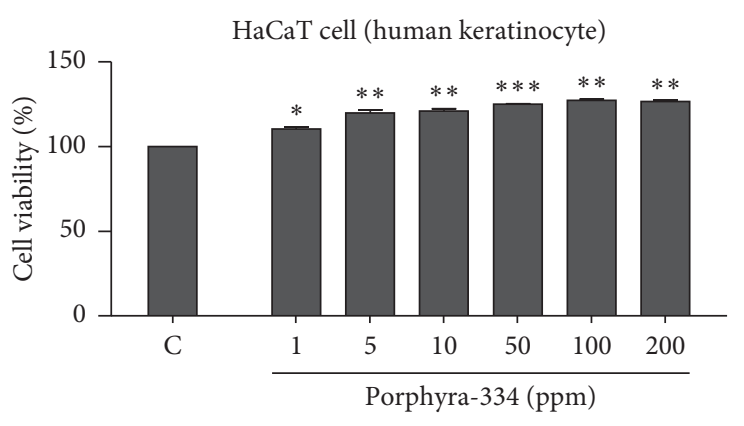

(a)

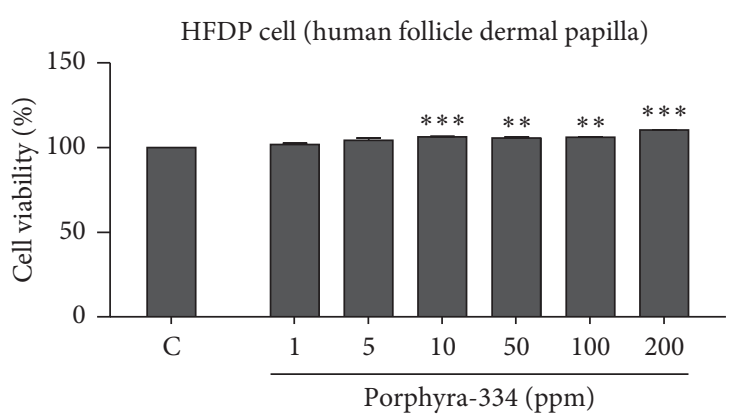

(b)

FIGURE 2: In vitro assessment of the effect of different concentrations of porphyra-334 on cell viability in HaCaT and HFDP cells. The effect of six different concentrations $(1,5,10,50,100$, and 200 ppm) of porphyra-334 on cell viability was examined in HaCaT (a) and HFDP (b) cells by MTT assay. Control (c) indicates cells treated with distilled water. For the comparisons between the positive sample (TGF- $\beta 1$ ) and the treatment group, we conducted independent $t$-tests. ${ }^{*} p<0.05,{ }^{* *} p<0.01$, and ${ }^{* * *} p<0.001$.

TABLe 1: Measurement of improvement of periorbital wrinkling according to six parameters.

\begin{tabular}{|c|c|c|c|c|c|c|c|c|}
\hline \multirow{2}{*}{ Evaluation parameter } & \multirow{2}{*}{ Time point } & \multicolumn{3}{|c|}{ Test group } & \multicolumn{3}{|c|}{ Control group } & \multirow{2}{*}{$\begin{array}{c}\text { Test/Control } \\
p \text { value }\end{array}$} \\
\hline & & Mean \pm SD & Change (\%) & $p$ value $\dagger$ & Mean \pm SD & Change (\%) & $p$ value $\dagger$ & \\
\hline \multirow{3}{*}{$\mathrm{R} 1$} & Baseline & $0.223 \pm 0.050$ & - & - & $0.214 \pm 0.051$ & - & - & - \\
\hline & $6 \mathrm{~W}$ & $0.211 \pm 0.052$ & -5 & 0.1 & $0.205 \pm 0.054$ & -3 & $\leq 0.001^{*}$ & 0.7 \\
\hline & $12 \mathrm{~W}$ & $0.198 \pm 0.040$ & -10 & 0.2 & $0.209 \pm 0.048$ & -1 & 0.5 & $0.047^{\#}$ \\
\hline \multirow{3}{*}{$\mathrm{R} 2$} & Baseline & $0.138 \pm 0.033$ & - & - & $0.131 \pm 0.027$ & - & - & - \\
\hline & $6 \mathrm{~W}$ & $0.130 \pm 0.030$ & -6 & $0.007^{*}$ & $0.136 \pm 0.037$ & 3.3 & 0.3 & $0.040^{\#}$ \\
\hline & $12 \mathrm{~W}$ & $0.120 \pm 0.024$ & -12 & $\leq 0.001^{*}$ & $0.137 \pm .035$ & 4.7 & 0.2 & $\leq 0.001^{\#}$ \\
\hline \multirow{3}{*}{ R3 } & Baseline & $0.100 \pm 0.025$ & - & - & $0.097 \pm 0.020$ & - & - & - \\
\hline & $6 \mathrm{~W}$ & $0.093 \pm 0.025$ & -7 & $\leq 0.001^{*}$ & $0.100 \pm 0.025$ & 2.9 & 0.2 & $0.003^{\#}$ \\
\hline & $12 \mathrm{~W}$ & $0.087 \pm 0.021$ & -13 & $\leq 0.001^{*}$ & $0.098 \pm 0.022$ & 1.1 & 0.7 & $\leq 0.001^{\#}$ \\
\hline \multirow{3}{*}{ R4 } & Baseline & $0.125 \pm 0.034$ & - & - & $0.120 \pm 0.035$ & - & - & - \\
\hline & $6 \mathrm{~W}$ & $0.117 \pm 0.034$ & -5 & 0.1 & $0.111 \pm 0.037$ & -7 & 0.1 & 0.8 \\
\hline & $12 \mathrm{~W}$ & $0.112 \pm 0.026$ & -8 & $0.006^{*}$ & $0.115 \pm 0.035$ & -3 & 0.3 & 0.4 \\
\hline \multirow{3}{*}{ R5 } & Baseline & $0.042 \pm 0.014$ & - & - & $0.039 \pm 0.012$ & - & - & - \\
\hline & $6 \mathrm{~W}$ & $0.039 \pm 0.014$ & -7 & 0.1 & $0.036 \pm 0.014$ & -7 & 0.1 & 1 \\
\hline & $12 \mathrm{~W}$ & $0.037 \pm 0.013$ & -11 & $0.008^{\dagger}$ & $0.037 \pm 0.010$ & -1 & 0.3 & 0.4 \\
\hline \multirow{3}{*}{ Visual assessment } & Baseline & $4.409 \pm 1.141$ & - & - & $4.318 \pm 1.171$ & - & - & - \\
\hline & $6 \mathrm{~W}$ & $4.182 \pm 1.532$ & -8 & 0.1 & $4.500 \pm 1.439$ & 3.2 & $0.042^{*}$ & $0.007^{\ddagger}$ \\
\hline & $12 \mathrm{~W}$ & $4.000 \pm 1.345$ & -11 & $0.003^{\dagger}$ & $4.455 \pm 1.371$ & 2.5 & 0.1 & $\leq 0.001^{*}$ \\
\hline
\end{tabular}

baseline in the control group. In comparisons between groups, average roughness values were significantly higher in the test group than those in the control group at 6 weeks and 12 weeks $(p=0.003$ and $p \leq 0.001$, respectively) (Table 1 and Figure 3(a)).

In the case of R1 (skin roughness), there was no significant difference at 6 weeks or 12 weeks as compared to baseline in the test group (Table 1 and Figure $3(\mathrm{~b})$ ). In the control group, skin roughness values were significantly reduced only at 6 weeks $(p=0.001)$ as compared to baseline. There was a significant difference in R1 $(p=0.047)$ between the test group and the control group only at 12 weeks (Table 1 and Figure 3(b)).

For the measurement of R2 (maximum roughness), we found a significant reduction at both 6 weeks $(p=0.007)$ and 12 weeks $(p \leq 0.001)$ as compared to baseline in the test group (Table 1 and Figure 3(c)). However, there was no difference in maximum roughness at either time point as compared to baseline in the control group (Table 1 and Figure 3(c)). In addition, we found that there were significant differences in maximum roughness values between the test and the control groups at 6 weeks $(p=0.040)$ and 12 weeks $(p \leq 0.001)$.

In the case of R4 (smoothness depth), there was a significant reduction only at 12 weeks $(-8.037 \%)(p=0.006)$ as compared to baseline in the test group (Table 1 and Figure $3(\mathrm{~d})$ ). For the R5 (arithmetic average roughness) measurement, the test group at 12 weeks $(-11.071 \%)$ $(p=0.008)$ showed a strong reduction as compared to baseline (Table 1 and Figure 3(e)). There was no difference between the groups for smoothness depth (Table 1 and Figure 3(e)). 


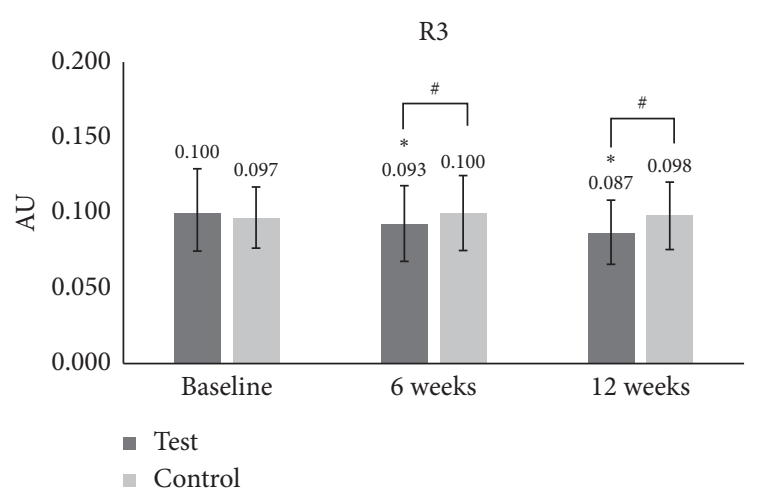

(a)

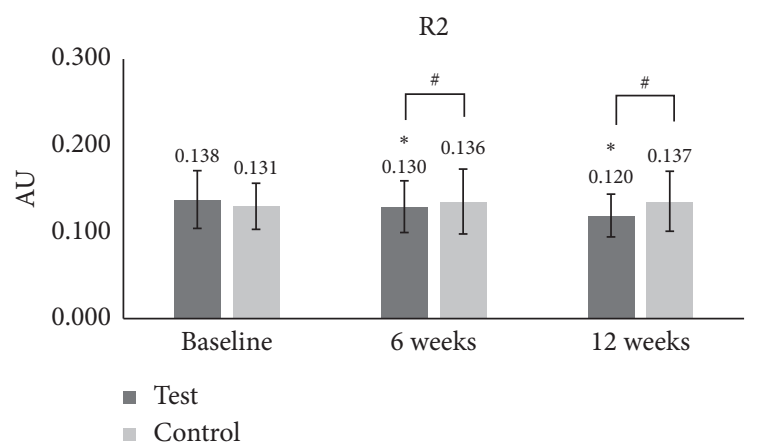

(c)

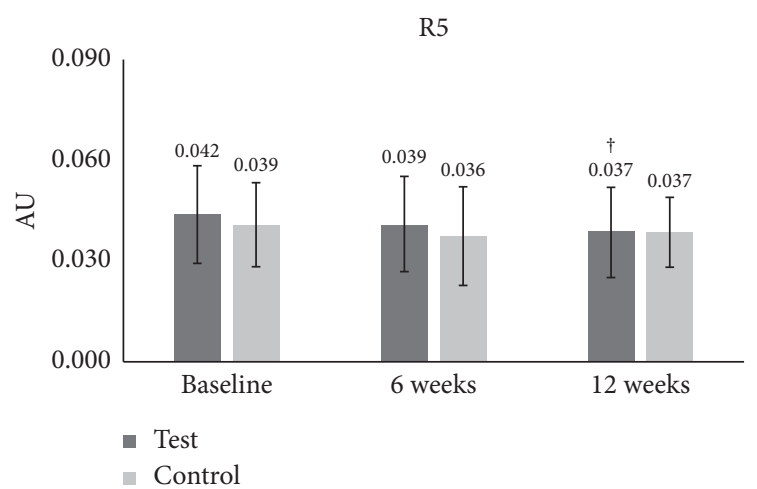

(e)

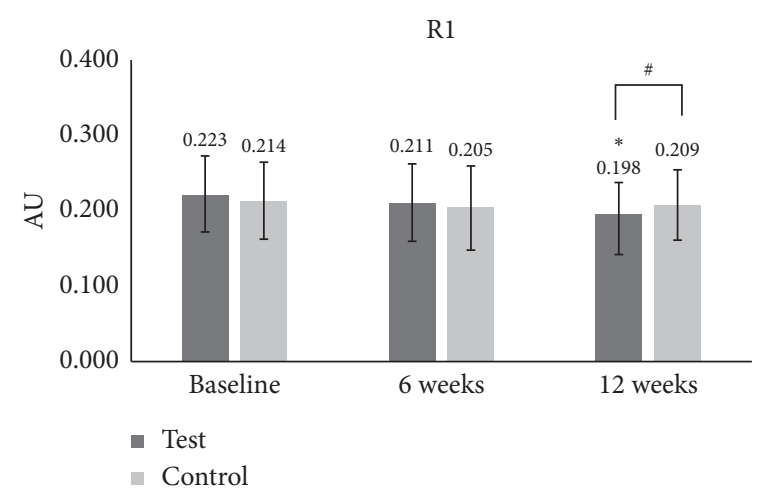

(b)

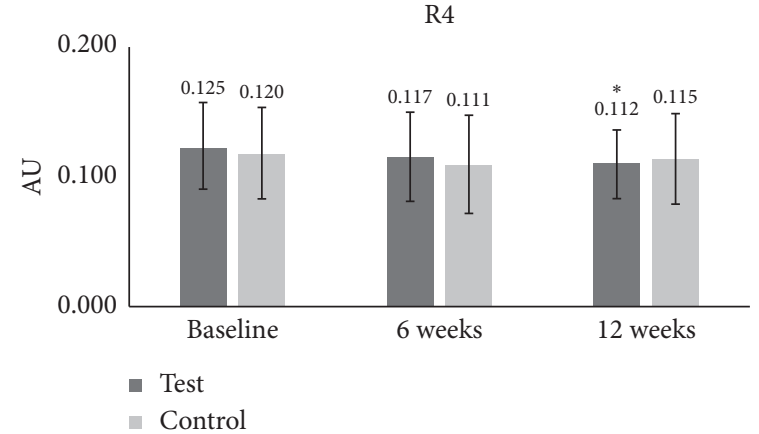

(d)

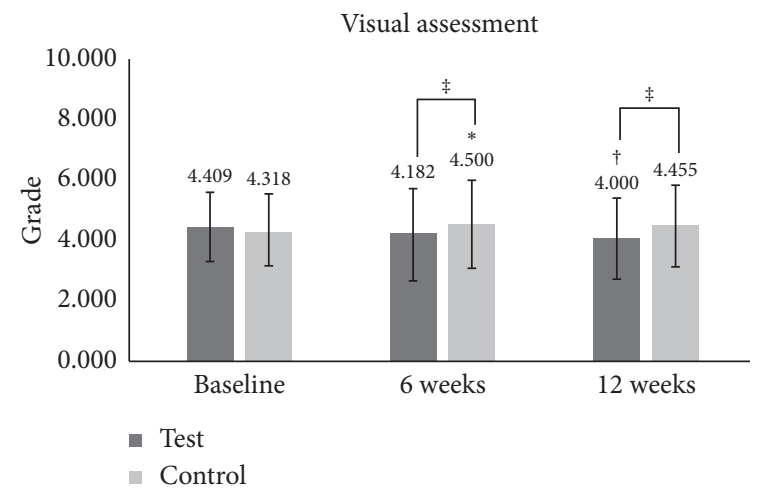

(f)

FIgURE 3: Clinical tests of porphyra-334 for improving periorbital wrinkles. Test (containing porphyra-334 (10 ppm)) and control (without porphyra-334) products were used. Six periorbital wrinkling parameters ((a) R3, average roughness; (b) R1, skin roughness; (c) R2, maximum roughness; (d) R4, smoothness depth; (e) R5, arithmetic average roughness, and (f) visual assessment) were measured for 22 participants at three different time points: baseline, 6 weeks $(6$ (W), and 12 weeks (12 (W). For the comparisons with baseline, we conducted paired samples $t$-tests. ${ }^{*}$ indicates $p<0.05$. For the comparisons between the test group and the control group, we used independent $t$-tests. ${ }^{\#}$ indicates $p<0.05$. For the visual assessment, we used the Wilcoxon signed ranks test and Mann-Whitney $U$ test. ${ }^{\dagger} p<0.05$. ${ }^{\ddagger} p<0.05$. $\mathrm{AU}=$ arbitrary unit.

According to a visual assessment of periorbital wrinkling, there was a significant reduction at 12 weeks $(-10.952 \%)(p=0.003)$ in the test group, while in the control group, the periorbital wrinkling was increased at 6 weeks $(3.225 \%)(p=0.042)$ (Table 1 and Figure 3(f)). There were significant differences in periorbital wrinkling between the two groups at 6 weeks $(p=0.007)$ and 12 weeks $(p \leq 0.001)$ (Table 1 and Figure 3(f)).

Six periorbital wrinkling parameters (R1, skin roughness; R2, maximum roughness; R3, average roughness; R4, smoothness depth; R5, arithmetic average roughness, and visual assessment) were measured at three different time points: baseline, 6 weeks $(6 \mathrm{~W})$, and 12 weeks $(12 \mathrm{~W})$. In the case of R1-R4, two different statistical analyses (paired samples $t$-test ${ }^{*}$ and independent $t$-test ${ }^{*}$ ) were carried out. * $p$ values for $t$-test comparisons with baseline values; ${ }^{*}$ indicates $p<0.05 ;^{* *}$ indicates $p<0.01 ;^{* * *}$ indicates $p<0.001$. $^{*} p$ values for $t$-test comparisons between values in the test group and the control group; ${ }^{*}$ indicates $p<0.05$. In the case of R5 and visual assessment, statistical analyses were 
carried out as follows. ${ }^{\dagger}: p<0.05$ by Wilcoxon signed ranks test. ${ }^{*}: p<0.05$ by paired samples $t$-test. ${ }^{\ddagger}: p<0.05$ by Mann-Whitney $U$ test. ${ }^{\dagger} p$ values for $t$-test comparisons between values in the test group and the control group; ${ }^{\dagger} p<0.05 ;{ }^{\dagger \dagger} p<0.01$. Change $(\%)=[$ (value after treatment-value before treatment)/value before treatment]x100.

Three biological samples from control (distilled water) and treatment (10 ppm of porphyra-334) HFDP cells were used for library preparation followed by paired-end sequencing with NovaSeq 6000.

3.5. Transcriptome Profiling of HFDP Cells in response to Porphyra-334 Treatment by RNA-Seq. Although porphyra334 has a wide range of important roles, the genomewide expression profile for human genes in response to porphyra334 treatment has not been established. In this study, we performed RNA-seq to establish transcriptome profiling in response to porphyra-334 treatment. The MTT assays demonstrated that the cell viability and proliferation in HFDP cells treated with porphyra-334 were the lowest among the three different human cell lines. However, porphyra-334 treatment in HFDP cells might result in dramatic changes in the transcriptome. Moreover, it might be of interest to examine the possible role of porphyra-334 in the promotion of hair follicle development by RNA-seq. We selected $10 \mathrm{ppm}$ of porphyra-334, which was shown to increase cell viability with strong statistical significance for RNA-seq.

HFDP cells were treated with $10 \mathrm{ppm}$ of porphyra-334 (treatment) or distilled water (control). After $24 \mathrm{~h}$, we harvested the cells and extracted total RNAs. The extracted total RNAs were used for mRNA library preparation as described previously. Three independent biological replicates for each condition were used for library preparation. A total of six libraries were paired-end sequenced using the NovaSeq 6000 system (Table 2). The number of sequence reads ranged from 40, 123, 294 (T2) to 51, 733, 698 (C3) (Figure 4(a)). The low-quality sequences from the obtained raw data were trimmed with a quality score of 20 . The ratio of bases with Phred quality scores of more than 20 ranged from $98.46 \%$ to $98.61 \%$, demonstrating the high quality of RNA-seq (Table 2). The proportion of mapped reads on the human transcriptome containing 159,998 transcripts ranged from $92.79 \%$ (T3) to $96.21 \%$ (T1) (Figure 4(a)). The number of mapped reads from each library was used for normalization using the DESeq2 method implemented in GENAVi (https://junkdnalab.shinyapps.io/GENAVi/). An adjusted $p$ value less than 0.01 and a fold change of more than 2 were used for thresholds to identify DEGs (Figure 4(b)). Finally, we identified 27 upregulated genes (39 transcripts) and 16 downregulated genes (43 transcripts) (Tables 3 and 4).

3.6. Identification of DEGs in HFDP Cells in response to Porphyra-334 Treatment. Of the identified DEGs, there were several different transcripts transcribed from a single gene. For example, three BIRC5 transcripts, three ETV1 transcripts, and four PTTG1 transcripts were upregulated (Table 3), while 10 IL1R1 transcripts, 12 OSBPL8 transcripts, and three SLC6A6 transcripts were downregulated by porphyra-334 (Table 4). To find enriched functions in the identified DEGs, we carried out GO enrichment analysis using the WebGestalt program. According to biological function for the 27 upregulated genes, GO terms were associated with cellular response to different metal ions (GO: 0097501), such as stress response to copper ion (GO: 1990169), cellular response to zinc ion (GO:0071294), and cellular response to cadmium ion (GO:0071276) (Table S1 and Figure 5(a)). Three genes (MT1E, MT1X, and MT2A), which are members of the metallothionein (MT) family, were involved in the detoxification of the inorganic compound (GO:0061687). In addition, four upregulated genes (MAD2L1, NCAPG, NEK2, and PTTG1) were involved in mitotic sister chromatid segregation (GO:0000070), sister chromatid segregation (GO:0000819), and nuclear chromosome segregation (GO:0098813). Two upregulated genes, MT1X and MT2A, were involved in the cellular response to erythropoietin (GO:0036018). According to the cellular component, several GO terms associated with chromosomal part were enriched (Table S1 and Figure 5(b)): chromosome centromeric region (GO:0000775), condensed chromosome (GO:0000793), and kinetochore (GO:0000776). In particular, four genes (BIRC5, MAD2L1, NCAPG, and NEK2) were associated with the chromosomal region (GO:0098687). Additionally, we identified an enriched metabolic pathway (mineral absorption (hsa04978)) according to the KEGG database. Four genes (MT1E, MT1L, MT1X, and MT2A) were involved in zinc homeostasis (WP3529) and copper homeostasis (WP3286) according to WikiPathways.

3.7. Gene Expression Profile of Hair Cycle and Hair Follicle Structure-Associated Genes. We examined the expression of selected genes associated with the hair cycle based on the previous study (Table 5). Out of 27 hair cycle-associated genes, BMP2 encoding bone morphogenetic protein 2, CYP1A1 encoding cytochrome P450 family 1 subfamily A member 1 , CYP27B1 encoding cytochrome P450 family 1 subfamily B member 1 , and WNT5A encoding Wnt family member $5 \mathrm{~A}$ were significantly upregulated by porphyra-334 treatment. Next, we examined the expression of 10 selected genes associated with the hair follicle structure (Table S2). Several keratin genes, such as KRT33 B, KRT34, and KRT79, were upregulated, while the KRT16 gene was downregulated by porphyra-334 treatment. In addition, $\mathrm{CDH} 3$ encoding P-cadherin 3 and $\mathrm{TCHH}$ encoding trichohyalin were upregulated. Out of nine selected genes associated with the epidermal structure, DSG1 encoding desmoglein (Dsg) 1 and KRT1 encoding keratin 1 protein were strongly upregulated, while DSC1, DSP, FLG, and PLEC genes were downregulated (Table S2). Of 10 selected genes associated with stem cells, CD34, KRT15, and SOX9 were significantly upregulated (Table S2).

\section{Discussion}

Human aging is a natural process accompanied by a decline in physiological and psychological functions. Intrinsic aging and photoaging cause skin aging, with diverse signs such as 
TABLE 2: Summary of raw data of six different libraries used for RNA-seq.

\begin{tabular}{lccccc}
\hline Library & Description & Total read bases (bp) & GC (\%) & Q20 (\%) & Accession no. \\
\hline C1 & Control replicate 1 & $4,499,074,492$ & 50.97 & 98.46 & SRR12641546 \\
C2 & Control replicate 2 & $4,422,011,694$ & 50.65 & 98.55 & SRR12641545 \\
C3 & Control replicate 3 & $5,225,103,498$ & 50 & 98.55 & SRR12641544 \\
T1 & Treatment replicate 1 & $4,681,863,888$ & 48.21 & 98.61 & SRR12641549 \\
T2 & Treatment replicate 2 & $4,052,452,694$ & 50.08 & 98.57 & SRR12641548 \\
T3 & Treatment replicate 3 & $4,354,746,704$ & 50.08 & 98.58 & SRR12641547 \\
\hline
\end{tabular}

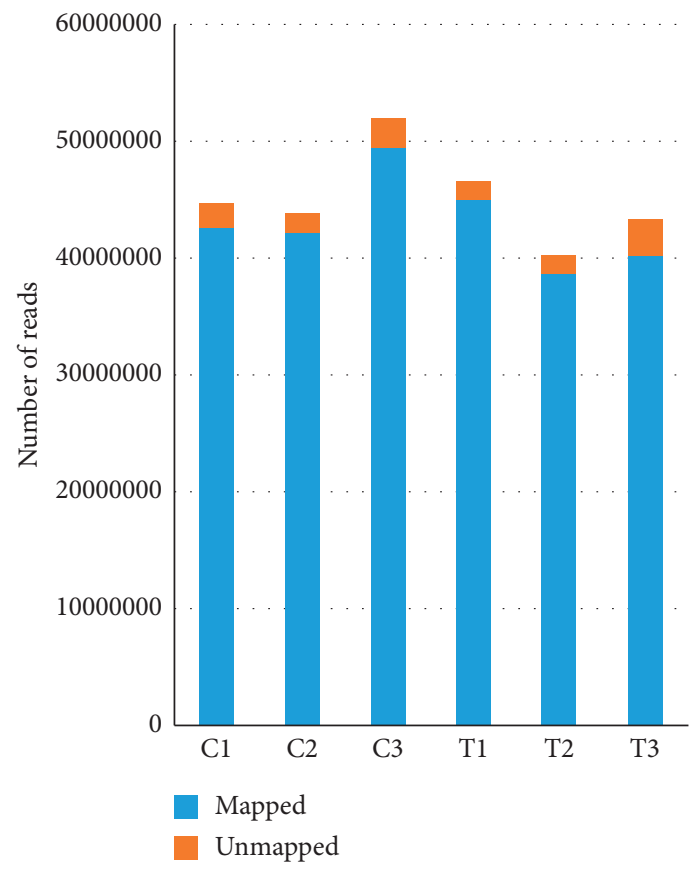

(a)

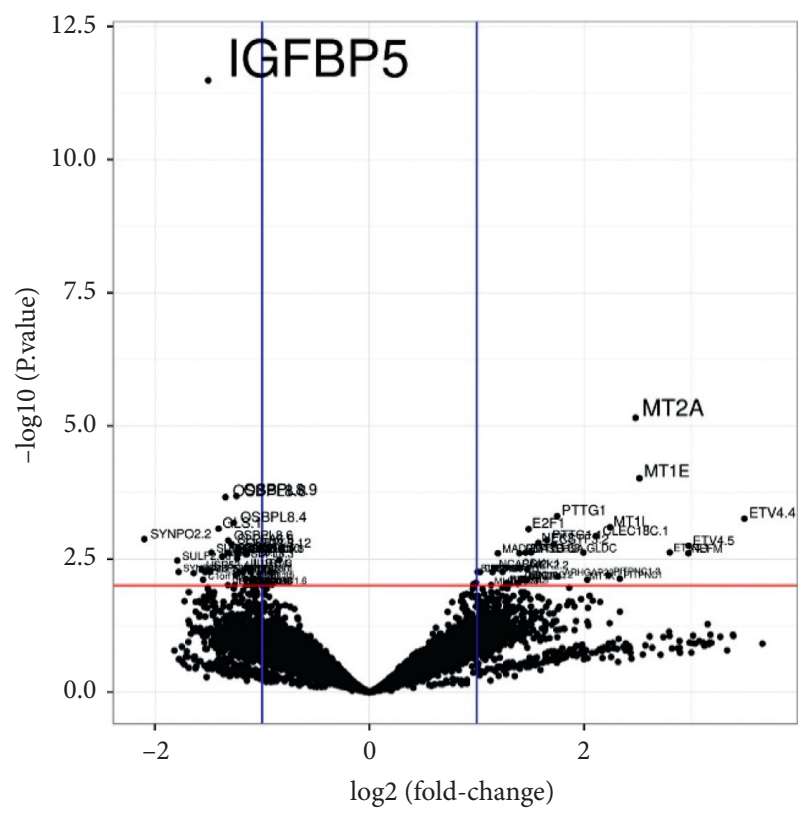

(b)

FIgURe 4: Mapping results and visualization of DEGs. (a) Proportion of mapped (blue) and unmapped (orange) reads on human reference transcriptome. (b) Volcano plot displaying the distribution of $\log 10$ (padj) and $\log 2$ (FC) for all expressed genes. Padj and FC indicate the adjusted $p$ value and fold change, respectively. DEGs are indicated by individual transcript names.

changes in skin tone, elasticity, vasodilation, and wrinkles. In particular, wrinkles can be easily affected by age and various stresses, including UV irradiation, which causes skin inflammation, pigmentation, and skin cancer. The photoaging induced by UV irradiation reduces collagen formation and induces the expression of matrix metalloproteinases (MMPs), resulting in wrinkle formation [28]. MMPs degrade extracellular matrix (ECM) components, such as collagen, elastin, and gelatin. Of the known MMPs, MMP1 encodes interstitial collagenase, specifically degrading the collagen triple helix, while $M M P 2$ encodes gelatinase A, degrading denatured collagen, gelatin, and elastin [29]. About $30 \%$ of the human body's proteins are collagen. Bundles of collagen molecules referred to as collagen fibers are the largest components of the ECM, providing the strength and elasticity of human tissues and organs [30]. Mature type I collagen fibers are synthesized by type I procollagen molecules, which are composed of two proalpha-1 chains (COL1A1) and one pro-alpha-2 chain (COL1A2) [31].
Porphyra-334 treatment led to a dramatic increase of collagen synthesis in Detroit 551 cells. In particular, the effect of 1 ppm of porphyra-334 on collagen synthesis was higher than that of TGF- $\beta 1$ used as a positive control, which promotes the collagen formation of dermal fibroblasts [27]. Although porphyra extract containing porphyra-334 and other MAAs also promoted collagen synthesis, the effect of purified porphyra-334 on collagen synthesis was much better. Moreover, as the concentration of porphyra-334 was increased, the effect on collagen synthesis increased. Thus, these results indicate that porphyra-334 might be a potential molecule for the promotion of collagen synthesis. By contrast, PIP contents in HFDP cells were decreased after different concentrations of porphyra-334 treatment. Moreover, PIP was not expressed in HaCaT cells. These results suggest the cell-specific expression of PIP.

Our study demonstrated that the effects of porphyra-334 on cell viability and proliferation were dependent on the cell type, and the increase of cell viability by porphyra-334 was the highest in $\mathrm{HaCaT}$ cells among the three tested cell types. 
TABle 3: Twenty-seven identified genes (39 transcripts) in HFDP cells upregulated by porphyra-344 treatment.

\begin{tabular}{|c|c|c|c|c|}
\hline Transcripts & $\log 2 \mathrm{FC}$ & Padj & baseMean & Function \\
\hline ARHGAP22.11 & 1.755275 & 0.006663 & 76.14885 & Rho GTPase activating protein 22 \\
\hline BIRC5 & 1.14606 & 0.00556 & 202.0075 & Baculoviral IAP repeat containing 5 \\
\hline BIRC5.3 & 1.007038 & 0.005512 & 275.2747 & Baculoviral IAP repeat containing 5 \\
\hline BIRC5.4 & 1.147806 & 0.005512 & 238.167 & Baculoviral IAP repeat containing 5 \\
\hline CDCA5.8 & 1.030194 & 0.005554 & 329.4237 & Cell division cycle-associated 5 \\
\hline CDK1.1 & 1.385413 & 0.004592 & 278.7067 & Cyclin-dependent kinase 1 \\
\hline CDK1.2 & 1.416186 & 0.007478 & 332.39 & Cyclin-dependent kinase 1 \\
\hline CLEC18C.1 & 2.110853 & 0.001172 & 137.6678 & C-type lectin domain family 18 member C \\
\hline CSTF3.2 & 1.719642 & 0.001671 & 126.3606 & Cleavage stimulation factor subunit 3 \\
\hline E2F1 & 1.483035 & $8.70 E-04$ & 318.3527 & E2F transcription factor 1 \\
\hline ETV4.1 & 2.798138 & 0.002372 & 87.71273 & ETS variant transcription factor 4 \\
\hline ETV4.4 & 3.493913 & $5.53 E-04$ & 78.42156 & ETS variant transcription factor 4 \\
\hline ETV4.5 & 2.97535 & 0.001792 & 76.19139 & ETS variant transcription factor 4 \\
\hline FOXL1 & 1.381458 & 0.009339 & 824.6779 & Forkhead box L1 \\
\hline GLDC & 1.994842 & 0.002396 & 317.7404 & Glycine decarboxylase \\
\hline MAD2L1 & 1.197541 & 0.002461 & 655.8934 & Mitotic arrest deficient 2 like 1 \\
\hline MAFF & 1.468844 & 0.007739 & 443.0851 & MAF bzip transcription factor $\mathrm{F}$ \\
\hline MLPH.3 & 1.133679 & 0.009733 & 169.9009 & Melanophilin \\
\hline MT1E & 2.516623 & $9.64 E-05$ & 1380.143 & Metallothionein $1 \mathrm{E}$ \\
\hline MT1L & 2.242355 & $8.01 E-04$ & 1228.073 & Metallothionein $1 \mathrm{~L}$ \\
\hline MT1X & 2.03042 & 0.007739 & 520.5107 & Metallothionein $1 \mathrm{X}$ \\
\hline MT2A & 2.480677 & $7.07 E-06$ & 38795.66 & Metallothionein 2A \\
\hline NCAPG & 1.240566 & 0.005512 & 185.8562 & Non-SMC condensin II complex subunit G2 \\
\hline NCAPG.2 & 1.162677 & 0.004724 & 174.1935 & Non-SMC condensin II complex subunit G2 \\
\hline NEFM & 2.973343 & 0.002461 & 84.93233 & Neurofilament medium \\
\hline NEK2 & 1.575009 & 0.001569 & 163.8964 & NIMA related kinase 2 \\
\hline NEK2.2 & 1.470924 & 0.004974 & 127.0178 & NIMA related kinase 2 \\
\hline PITPNC1 & 2.332033 & 0.007432 & 171.0734 & Phosphatidylinositol transfer protein cytoplasmic 1 \\
\hline PITPNC1.3 & 2.228156 & 0.006396 & 132.9353 & Phosphatidylinositol transfer protein cytoplasmic 1 \\
\hline PTTG1 & 1.749011 & $4.96 E-04$ & 328.4098 & PTTG1 regulator of sister chromatid separation \\
\hline PTTG1.1 & 1.654699 & 0.001396 & 457.2504 & PTTG1 regulator of sister chromatid separation \\
\hline PTTG1.2 & 1.507915 & 0.002372 & 653.1276 & PTTG1 regulator of sister chromatid separation \\
\hline PTTG1.3 & 1.456208 & 0.002396 & 503.3174 & PTTG1 regulator of sister chromatid separation \\
\hline RIN1.1 & 1.280807 & 0.008849 & 188.6867 & Ras and Rab interactor 1 \\
\hline RIN1.3 & 1.28142 & 0.009534 & 221.4613 & Ras and Rab interactor 1 \\
\hline RNASEH2A & 1.397449 & 0.002461 & 211.7831 & Ribonuclease $\mathrm{H} 2$ subunit A \\
\hline SEC11C.2 & 1.445373 & 0.007432 & 138.2534 & Signal peptidase complex subunit \\
\hline SHISA2 & 1.314314 & 0.009339 & 142.4822 & Shisa family member 2 \\
\hline UBE2S.1 & 1.445318 & 0.007739 & 2929.009 & Ubiquitin-conjugating enzyme E2 S \\
\hline
\end{tabular}

Abbreviations: fold change (FC), padj (adjusted $p$ value), baseMean (average of normalized count values).

Porphyra-334 also statistically significantly increased the cell viability of HFDP cells; however, cell viability was not significantly changed in Detroit 551 cells. Of the different concentrations of porphyra-334, the application of $10 \mathrm{ppm}$ of porphyra-334 showed a significant increase in cell viability, while 1 and 5 ppm of porphyra-334 did not show any increase of cell viability. This result suggests that the optimal concentration of porphyra-334 should be applied for cosmetic purposes.

The in vivo clinical test with 22 participants demonstrated the effect of porphyra-334 (10 ppm) on the reduction of periorbital wrinkles. Of the six examined parameters of periorbital wrinkles, three (R3 (average roughness), R2 (maximum roughness), and visual assessment)) were significantly different between the treatment and control groups at both 6 and 12 weeks. Our recent study showed the improvement of periorbital wrinkles by Leontopodium Alpinum callus culture extract (LACCE) [32]. Similarly, a recent study using a cream containing low-molecular-weight heparan sulfate (LMW-HS) and a mixture of four different naturally derived plant extracts showed the improvement of periorbital wrinkles [33]. However, we showed the usefulness of porphyra-334 as a single molecule for the reduction of periorbital wrinkles as compared to the other two studies.

Next-generation sequencing (NGS) is currently used for a wide range of molecular studies. RNA-seq based on the NGS technique can reveal the presence and quantity of RNA in a specific biological sample. RNA-seq is particularly useful to analyze the genomewide transcriptome change by a specific treatment. In this study, we carried out transcriptome profiling of HFDP cells, which were isolated from the hair papilla of normal human scalp hair follicles in response to porphyra-334 treatment. It was of interest to examine the effects of porphyra-334 in different human cell lines. However, due to financial constraints, we selected HFDP cells to study the potential roles of porphyra-334 in 
TABLE 4: Sixteen identified genes (43 transcripts) in HFDP cells downregulated by porphyra-334 treatment.

\begin{tabular}{|c|c|c|c|c|}
\hline Transcripts & $\log 2 \mathrm{FC}$ & Padj & baseMean & Function \\
\hline TXNRD1.6 & -1.04581 & 0.009608 & 1816.645 & Thioredoxin reductase 1 \\
\hline C1orf198 & -1.50685 & 0.010883 & 934.3319 & Chromosome 1 open reading frame 198 \\
\hline C1orf198.3 & -1.55059 & 0.007739 & 1214.224 & Chromosome 1 open reading frame 198 \\
\hline DHCR7.2 & -1.32018 & 0.009763 & 333.9369 & 7-Dehydrocholesterol reductase \\
\hline GLS.1 & -1.40756 & $8.57 E-04$ & 363.402 & Glutaminase \\
\hline IGFBP5 & -1.5019 & $3.25 E-12$ & 4046.24 & Insulin-like growth factor binding protein 5 \\
\hline IL1R1 & -1.07412 & 0.007432 & 1560.642 & Interleukin 1 receptor type 1 \\
\hline IL1R1.1 & -1.15299 & 0.007432 & 1595.837 & Interleukin 1 receptor type 1 \\
\hline IL1R1.10 & -1.10651 & 0.00554 & 1810.324 & Interleukin 1 receptor type 1 \\
\hline IL1R1.11 & -1.10267 & 0.007796 & 1826.142 & Interleukin 1 receptor type 1 \\
\hline IL1R1.13 & -1.1043 & 0.009733 & 1556.153 & Interleukin 1 receptor type 1 \\
\hline IL1R1.15 & -1.08556 & 0.007432 & 1626.087 & Interleukin 1 receptor type 1 \\
\hline IL1R1.3 & -1.11215 & 0.004592 & 1519.688 & Interleukin 1 receptor type 1 \\
\hline IL1R1.4 & -1.14748 & 0.004604 & 1575.658 & Interleukin 1 receptor type 1 \\
\hline IL1R1.6 & -1.06183 & 0.009772 & 1515.673 & Interleukin 1 receptor type 1 \\
\hline IL1R1.9 & -1.07493 & 0.009772 & 1442.102 & Interleukin 1 receptor type 1 \\
\hline MINDY2.3 & -1.14843 & 0.009763 & 227.8405 & MINDY lysine 48 deubiquitinase 2 \\
\hline OSBPL8 & -1.20939 & 0.005512 & 928.14 & Oxysterol-binding protein like 8 \\
\hline OSBPL8.1 & -1.14638 & 0.002461 & 944.2872 & Oxysterol-binding protein-related protein 8 \\
\hline OSBPL8.10 & -1.23771 & 0.002396 & 949.3331 & Oxysterol-binding protein like 8 \\
\hline OSBPL8.11 & -1.37329 & 0.002848 & 1047.627 & Oxysterol-binding protein like 8 \\
\hline OSBPL8.12 & -1.21833 & 0.001988 & 977.1096 & Oxysterol-binding protein like 8 \\
\hline OSBPL8.3 & -1.23386 & 0.003057 & 885.1727 & Oxysterol-binding protein like 8 \\
\hline OSBPL8.4 & -1.26401 & $6.61 E-04$ & 1027.8 & Oxysterol-binding protein like 8 \\
\hline OSBPL8.5 & -1.22201 & 0.002396 & 989.3 & Oxysterol-binding protein like 8 \\
\hline OSBPL8.6 & -1.31677 & 0.001419 & 905.0201 & Oxysterol-binding protein like 8 \\
\hline OSBPL8.7 & -1.17836 & 0.00556 & 888.7467 & Oxysterol-binding protein like 8 \\
\hline OSBPL8.8 & -1.34186 & $2.18 E-04$ & 898.2552 & Oxysterol-binding protein like 8 \\
\hline OSBPL8.9 & -1.23957 & $2.08 E-04$ & 875.6725 & Oxysterol-binding protein like 8 \\
\hline RSPO3.2 & -1.63792 & 0.00581 & 95.73672 & R-spondin 3 \\
\hline SEMA5A.3 & -1.25554 & 0.009772 & 120.5946 & Semaphorin $5 \mathrm{~A}$ \\
\hline SEMA5A.7 & -1.24651 & 0.006395 & 128.2849 & Semaphorin $5 \mathrm{~A}$ \\
\hline SLC6A6 & -1.32467 & 0.002396 & 302.6643 & Solute carrier family 6 member 6 \\
\hline SLC6A6.5 & -1.2846 & 0.001671 & 302.9567 & Solute carrier family 6 member 6 \\
\hline SLC6A6.8 & -1.30774 & 0.002461 & 311.0602 & Solute carrier family 6 member 6 \\
\hline SULF1.12 & -1.4729 & 0.002396 & 122.1485 & Sulfatase 1 \\
\hline SULF2 & -1.52947 & 0.00554 & 89.47182 & Sulfatase 2 \\
\hline SULF2.10 & -1.79049 & 0.003386 & 76.78665 & Sulfatase 2 \\
\hline SYNPO2.1 & -1.77862 & 0.005512 & 663.7285 & Synaptopodin 2 \\
\hline SYNPO2.2 & -2.09818 & 0.001336 & 79.2225 & Synaptopodin 2 \\
\hline TXNRD1.3 & -1.15061 & 0.002461 & 2067.474 & Thioredoxin reductase 1 \\
\hline USP53.2 & -1.48485 & 0.005512 & 223.9112 & Ubiquitin specific peptidase 53 \\
\hline USP53.4 & -1.5656 & 0.004986 & 229.8406 & Ubiquitin specific peptidase 53 \\
\hline
\end{tabular}

the control of hair production and the hair growth cycle. RNA-seq identified several DEGs that were up- or downregulated by porphyra-334 treatment. Of the identified DEGs, there were multiple transcripts (isoforms) derived from the same gene in our study, and the isoforms showed similar expression patterns. This result suggests that the isoforms of the identified DEGs in this study had similar expression patterns, at least in HFDP cells. On the other hand, several other studies have reported that the differential expression of isoforms of a gene in different organs, tissues, cells, and developmental stages occurs very often [34, 35].

Gene enrichment analysis revealed that four genes MT1E, MT1L, MT1X, and MT2A encoding MTs were upregulated by porphyra-334 treatment. MTs are ubiquitous small cysteine-rich proteins containing two binding domains, $\alpha$ and $\beta$, which enable them to bind to several heavy metals, such as cadmium, copper, and zinc [36]. Due to their unique structural characteristics, MTs function in metal homeostasis [37] and protection against oxidative stresses [38]. Free radicals such as ROS and reactive nitrogen species (RNS) are generated by UV, X-ray, and gamma radiation, and they are responsible for aging and several human diseases, including DNA and cell damage and diverse cancers [39-41]. The functional roles of MTs as free-radical scavengers against ROS and RNS have been previously demonstrated $[42,43]$. In addition, MTs are involved in the inhibition of apoptosis [44] and carcinogenesis [45]. In humans, MTs have four different isoforms (MT1-MT4), and MT1 consists of eight known functional isoforms [45]. Based on the results, the overexpression of three MT1 isoforms and 


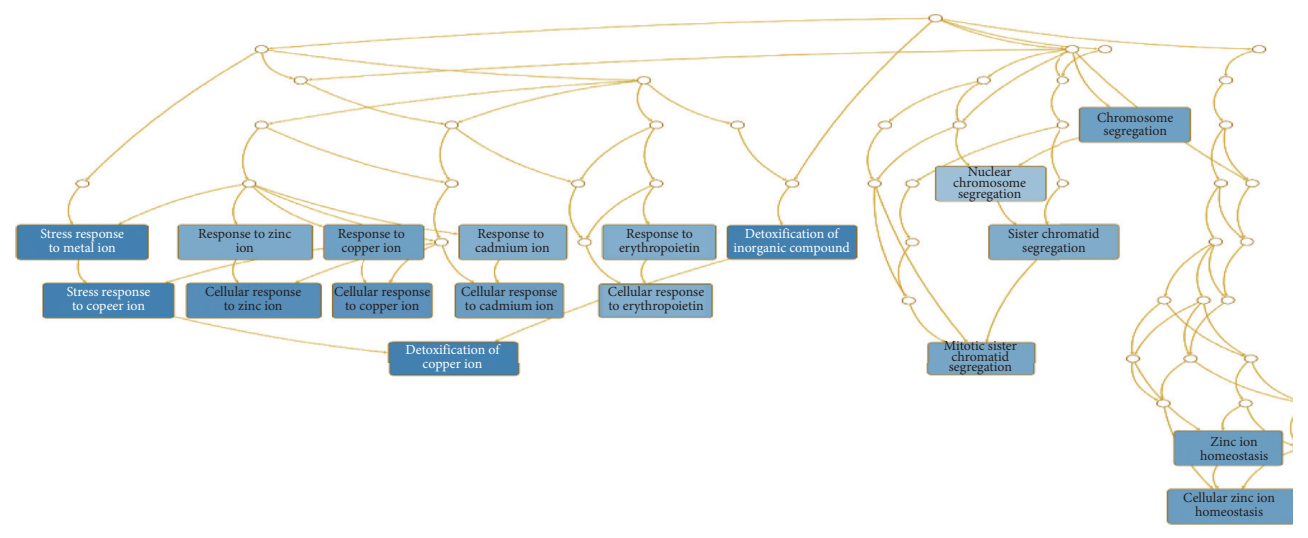

(a)

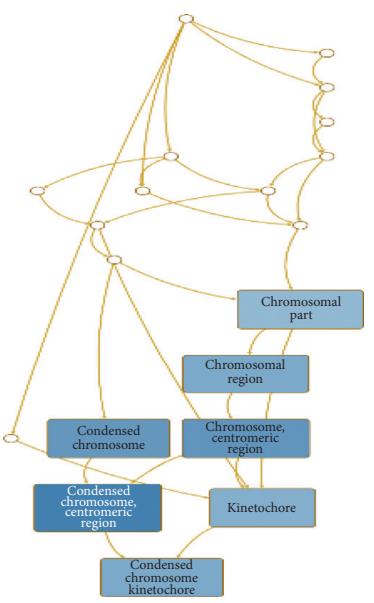

(b)

Figure 5: Hierarchical structure of identified enriched GO terms for upregulated genes in response to porphyra-334 treatment. DAGs visualize the hierarchical structure of identified enriched GO terms for upregulated genes in response to porphyra-334 treatment according to biological process (a) and cellular component (b). Each GO term is indicated by a different box color based on $p$ value. Detailed information on identified GO terms can be found in Table S1.

TABLE 5: Expression of 27 selected hair cycle-associated genes.

\begin{tabular}{|c|c|c|c|c|}
\hline Gene ID & Gene function & baseMean & log2FoldChange & $p$ value \\
\hline ADCY7 & Activin A receptor type 1 & 81.85136 & -0.53874 & 0.086809 \\
\hline BMP2 & Bone morphogenetic protein 2 & 1650.067 & 2.002074 & 0.027019 \\
\hline BMP7 & Bone morphogenetic protein 7 & 101.2629 & 0.332366 & 0.355265 \\
\hline $\mathrm{BNC1}$ & Basonuclin 1 & 22.58606 & 0.095093 & 0.866783 \\
\hline $\mathrm{BNC2}$ & Basonuclin 2 & 221.3541 & -0.75229 & 0.008525 \\
\hline CCNA2 & Cyclin A2 & 706.4942 & 0.597831 & 0.008916 \\
\hline CYP1A1 & Cytochrome P450 family 1 subfamily a member 1 & 10.70451 & 2.005344 & 0.034324 \\
\hline CYP1B1 & Cytochrome P450 family 1 subfamily B member 1 & 26319.37 & -0.53917 & 0.006894 \\
\hline CYP27B1 & Cytochrome P450 family 27 subfamily B member 1 & 11.08607 & 1.019638 & 0.172368 \\
\hline DKK3 & Dickkopf 3 & 571.3778 & -0.06546 & 0.780174 \\
\hline FGF18 & Fibroblast growth factor 18 & 57.2295 & 0.752468 & 0.10097 \\
\hline FGF5 & Fibroblast growth factor 5 & 272.1485 & -0.41585 & 0.235221 \\
\hline FZD10 & Frizzled 10 & 13.12887 & 0.504148 & 0.465732 \\
\hline FZD3 & Frizzled 3 & 29.57211 & 0.769263 & 0.099251 \\
\hline HSD17B14 & Hydroxysteroid 17-beta dehydrogenase 14 & 30.8214 & -0.36653 & 0.440247 \\
\hline JAG1 & Jagged 1 & 1349.268 & -0.63115 & 0.012286 \\
\hline MMP7 & Matrix metalloproteinase 7 & 1.600479 & 0.689856 & 0.693773 \\
\hline MSX2 & Homeobox protein MSX2 & 83.5912 & -0.4325 & 0.187032 \\
\hline SFRP1 & Secreted frizzled-related protein 1 & 1530.066 & -0.03537 & 0.860464 \\
\hline SFRP2 & Secreted frizzled-related protein 2 & 307.8726 & -0.57658 & 0.042625 \\
\hline SOX10 & Sex determining region Y-box 10 & 2.098739 & -0.71721 & 0.748481 \\
\hline TCF7 & Transcription factor 7 & 4.502755 & 0.32334 & 0.754997 \\
\hline TGFB2 & Transforming growth factor-beta 2 & 70.37078 & 0.566863 & 0.205471 \\
\hline THBS2 & Thrombospondin 2 & 58576.05 & -0.40607 & 0.018489 \\
\hline VDR & Vitamin $D$ receptor & 689.8525 & -0.58772 & 0.127502 \\
\hline WNT3 & Wnt family member 3 & 100.6203 & 0.433119 & 0.225621 \\
\hline WNT5A & Wnt family member $5 \mathrm{~A}$ & 768.6411 & 1.30595 & 0.108462 \\
\hline
\end{tabular}

one MT2 isoform in the HFDP cells by porphyra-334 strongly suggests the potential antiaging effect of porphyra334 as an antioxidant cooperative with MTs in human cells. It might be of interest to examine the possible interaction of MTs with porphyra-334 in the near future.

Of the upregulated genes, $B I R C 5$, also known as survivin, is a member of the inhibitor of apoptosis protein (IAP) family and functions in the control of cell proliferation and inhibition of apoptosis [46]. A previous study showed that survivin is expressed in the proliferating keratinocytes of the hair matrix and outer root sheath of human anagen hair follicles [47]. UV-B induced the expression of survivin in human keratinocytes and mouse skin, suggesting the possible role of survivin in response to UV-B [48]. Furthermore, 
$\mathrm{Wnt} / \beta$-catenin signaling might control the expression of survivin in anagen hair follicles [47]. A previous study reported that cyclin-dependent kinase 1 (CDK1) is also upregulated in HDPC cells in response to platelet-rich plasma (PRP), which is plasma enriched with a higher proportion of platelets [49]. Thus, our results indicate that the overexpression of BIRC5 and CDK1 in HFDP cells by porphyra-334 might be associated with the promotion of hair follicle growth. However, further studies should be conducted to confirm our hypothesis.

Some genes upregulated by porphyra-334 are involved in carcinogenesis. For example, there have been reports of the promotion of colorectal cancer progression by cell division cycle-associated 5 (CDCA5) [50] and the functional role of E26 transformation-specific (ETS) variant 4 (ETV4) in pancreatic cancer [51]. The pathological significance of MAD2L1 in breast cancer [52]; the metastasis promotion of PITPNC1 by melanoma, breast cancer, and colon cancer cells [53]; and the suppression of breast tumors by RIN1 [54] have also been reported.

Two upregulated genes, E2F1 and FOXL1, were associated with cell proliferation. Moreover, the functional roles of E2F1 for the promotion of apoptosis and suppression of proliferation have been reported [55]. FOXL1 is a member of the forkhead box (Fox) transcription factor family, and it is involved in the regulation of epithelial cell proliferation in the gastrointestinal tract and the inhibition of growth and invasion in human pancreatic cancer cells [56].

One interesting finding was that three upregulated genes, $B I R C 5, M A D 2 L 1$, and NEK2, encoded proteins that are components of kinetochores. Kinetochores are large protein complexes assembled on the centromeric region of the chromosomes, and they mediate spindle-microtubule attachment and control the movement of chromosomes during mitosis and meiosis [57]. Moreover, porphyra-334 upregulated the expression of four genes, MAD2L1, NCAPG, NEK2, and PTTG1, required for nuclear chromosome segregation. These results suggest possible implications of porphyra-334 for chromosome segregation, which is essential for humans to maintain genome stability by mitotic and meiotic divisions [58].

Moreover, we also found that two genes, ARHGAP22 and PTTG1, were associated with cell structure and movement. For instance, ARHGAP22 is a member of the Rho family of small GTPases that regulate morphogenesis, polarity, movement, and cell division [59]. A previous study showed that ARHGAP22 localizes at endosomes and functions in the regulation of the actin cytoskeleton [60]. Pituitary tumor transforming gene 1 (PTTG1), also known as securin, has a wide range of functions, such as inhibition of sister chromatid separation and regulation of microtubule nucleation and cell migration [61].

Among the downregulated genes, many isoforms of IL1R1, OSBPL8, and SLC6A6 were coregulated. IL1R1 encodes interleukin 1 receptor, also called CD121a (Cluster of Differentiation 121a), which is a receptor for interleukin 1 alpha (IL1A), interleukin 1 beta (IL1B), and interleukin 1 receptor antagonist (IL1RA) [62]. IL1R1 transmits the signal of interleukin 1 involved in several cytokine-induced immune and inflammatory responses [62]. The downregulation of IL1R1 by porphyra-334 indicates that porphyra-334 might not be harmful to HFDP cells. OSBPL8 encoding SBP-related protein 8 (ORP8) is an endoplasmic reticulum sterol sensor functioning in cellular lipid metabolism. A previous study reported that the deficiency of the OSBPL 8 gene in mice resulted in the induction of highdensity lipoproteins [63]. It has been reported that SLC6A6 promotes the survival and multidrug resistance of colorectal cancer [64]. The potential roles of OSBPL8 and SLC6A6 associated with porphyra-334 should be further elucidated.

Based on RNA-seq data, we examined the expression of selected genes associated with the hair follicle cycle and structure. As we expected, several keratin genes, such as Keratin 1, Keratin 10, Keratin 15, Keratin 17, Keratin 33B, Keratin 34, and Keratin 79, were upregulated by porphyra334, suggesting possible implications of porphyra-334 for the epidermal structure and hair follicle structure. In particular, the expression of CHD3 encoding P-cadherin was upregulated by porphyra-334. It is known that P-cadherin plays an important role in human hair growth and cycling by regulating canonical Wnt signaling and inhibiting the expression of TGFB2 [65]. Similarly, the expression of WNT3 and WNT5A, which are members of the Wnt family, was upregulated by porphyra-334. However, porphyra-334 upregulated the expression of TGFB2 in our study. The detailed mechanism associated with Wnt signaling and TGFB2 expression regulated by porphyra-334 should be further elucidated. Dsgs are calcium-dependent transmembrane glycoproteins and are involved in keratinization, anchorage of the hair, and hypotrichosis [66]. Of the three DSG genes, DSG1 and DSG3 were upregulated, while DSG2 was downregulated. This result is consistent with the previous result showing that the expression of DSG1 and DSG3 was overlapped in the companion layer [67].

Although gene expression profiling of human keratinocyte cells in response to porphyra-334 has been reported previously [23], it was difficult for us to compare the previous results with our results due to differences in human cell lines, concentrations of porphyra-334, UVR treatments, and technical approaches such as microarray and RNA-seq. Therefore, it might be of interest to examine porphyra-334 effects in different human cell lines with or without UVR by RNA-seq for a detailed understanding of the functional roles of porphyra-334.

\section{Conclusion}

In this study, we examined the potential uses of porphyra334 as an antiaging agent, including the promotion of collagen formation, improvement of periorbital wrinkles, and promotion of cell proliferation, in three different human cell lines. Furthermore, the RNA-seq results confirmed the functional role of porphyra-334 as an antioxidant by upregulating the expression of several genes for MT. Moreover, porphyra-334 induced the expression of genes involved in nuclear chromosome segregation and the encoding of components of kinetochores. In addition, the upregulation of several genes, including many keratin genes 
associated with the hair follicle cycle, the hair follicle structure, the epidermal structure, and stem cells, suggests the potential role of porphyra-334 for hair follicle growth and maintenance. Taken together, we provided several new pieces of evidence of porphyra-334 as a potential antiaging cosmetic material and elucidated the expression network in HFDP cells in response to porphyra-334.

\section{Data Availability}

Six raw sequence datasets associated with this project were deposited in SRA database under PRJNA663440.

\section{Disclosure}

The funders had no role in study design, data collection and analysis, decision to publish, or preparation of the manuscript.

\section{Conflicts of Interest}

The authors declare that they have no conflicts of interest.

\section{Authors' Contributions}

Su Yeon Kim and Won Kyong Cho contributed equally to this work.

\section{Acknowledgments}

This research was supported by the project titled "Development of Advanced Process for Mass Production of Porphyra 334 (20190057)" funded by the Ministry of Oceans and Fisheries (for S. H. M).

\section{Supplementary Materials}

Table S1: enriched GO terms in 27 genes in HFDP cells upregulated by porphyra-334 treatment. Table S2: expression of selected genes involved in hair follicle structure, epidermal structure, and stem cells in HFDP cells in response to porphyra-334 treatment. (Supplementary Materials)

\section{References}

[1] J. Favre-Bonvin, N. Arpin, and C. Brevard, "Structure de la mycosporine (P 310)," Canadian Journal of Chemistry, vol. 54, no. 7, pp. 1105-1113, 1976.

[2] J. M. Shick and W. C. Dunlap, "Mycosporine-like amino acids and related gadusols: biosynthesis, accumulation, and UVprotective functions in aquatic organisms," Annual Review of Physiology, vol. 64, no. 1, pp. 223-262, 2002.

[3] C. A. Llewellyn and R. L. Airs, "Distribution and abundance of MAAs in 33 species of microalgae across 13 classes," Marine Drugs, vol. 8, no. 4, pp. 1273-1291, 2010.

[4] Y. Sun, N. Zhang, J. Zhou et al., "Distribution, contents, and types of mycosporine-like amino acids (MAAs) in marine macroalgae and a database for MAAs based on these characteristics," Marine Drugs, vol. 18, no. 1, p. 43, 2020.

[5] D. S. Mason, F. Schafer, J. M. Shick, and W. C. Dunlap, "Ultraviolet radiation-absorbing mycosporine-like amino acids (MAAs) are acquired from their diet by medaka fish (Oryzias latipes) but not by SKH-1 hairless mice," Comparative Biochemistry and Physiology Part A: Molecular \& Integrative Physiology, vol. 120, no. 4, pp. 587-598, 1998.

[6] S. J. Newman, W. C. Dunlap, S. Nicol, and D. Ritz, "Antarctic krill (Euphausia superba) acquire a UV-absorbing mycosporine-like amino acid from dietary algae," Journal of Experimental Marine Biology and Ecology, vol. 255, no. 1, pp. 93-110, 2000.

[7] C. Oyamada, M. Kaneniwa, K. Ebitani, M. Murata, and K. Ishihara, "Mycosporine-like amino acids extracted from scallop (Patinopecten yessoensis) ovaries: UV protection and growth stimulation activities on human cells," Marine Biotechnology, vol. 10, no. 2, pp. 141-150, 2008.

[8] K. T. Miyamoto, M. Komatsu, and H. Ikeda, "Discovery of gene cluster for mycosporine-like amino acid biosynthesis from Actinomycetales microorganisms and production of a novel mycosporine-like amino acid by heterologous expression," Applied and Environmental Microbiology, vol. 80, no. 16, pp. 5028-5036, 2014.

[9] R. Gacesa, K. P. Lawrence, N. D. Georgakopoulos et al., "The mycosporine-like amino acids porphyra-334 and shinorine are antioxidants and direct antagonists of Keap1-Nrf2 binding," Biochimie, vol. 154, pp. 35-44, 2018.

[10] K. P. Lawrence, P. F. Long, and A. R. Young, "Mycosporinelike amino acids for skin photoprotection," Current Medicinal Chemistry, vol. 25, no. 40, pp. 5512-5527, 2019.

[11] W. M. Bandaranayake, "Mycosporines: are they nature's sunscreens?" Natural Product Reports, vol. 15, pp. 159-172, 1998.

[12] A. Torres, C. D. Enk, M. Hochberg, and M. Srebnik, "Porphyra-334, a potential natural source for UVA protective sunscreens," Photochemical \& Photobiological Sciences, vol. 5, no. 4, pp. 432-435, 2006.

[13] F. R. Conde, M. S. Churio, and C. M. Previtali, "The photoprotector mechanism of mycosporine-like amino acids. Excited-state properties and photostability of porphyra-334 in aqueous solution," Journal of Photochemistry and Photobiology B: Biology, vol. 56, no. 2-3, pp. 139-144, 2000.

[14] M. Yoshiki, K. Tsuge, Y. Tsuruta et al., "Production of new antioxidant compound from mycosporine-like amino acid, porphyra-334 by heat treatment," Food Chemistry, vol. 113, no. 4, pp. 1127-1132, 2009.

[15] C. Tao, T. Sugawara, S. Maeda, X. Wang, and T. Hirata, "Antioxidative activities of a mycosporine-like amino acid, porphyra-334," Fisheries Science, vol. 74, no. 5, pp. 1166-1172, 2008.

[16] S. Takano, A. Nakanishi, D. Uemura, and Y. Hirata, "Isolation and structure of a $334 \mathrm{Nm}$ uv-absorbing substance, porphyra334 from the red algaporphyra tenerakjellman," Chemistry Letters, vol. 8, no. 4, pp. 419-420, 1979.

[17] L.-F. Chuang, H.-N. Chou, and P.-J. Sung, "Porphyra-334 isolated from the marine algae Bangia atropurpurea: conformational performance for energy conversion," Marine Drugs, vol. 12, no. 9, pp. 4732-4740, 2014.

[18] K. Ishihara, R. Watanabe, H. Uchida et al., "Novel glycosylated mycosporine-like amino acid, 13- O -( $\beta$-galactosyl)porphyra-334, from the edible cyanobacterium Nostoc sphaericum -protective activity on human keratinocytes from UV light," Journal of Photochemistry and Photobiology B: Biology, vol. 172, pp. 102-108, 2017.

[19] S. Bhatia, K. Sharma, A. Namdeo, B. Chaugule, M. Kavale, and S. Nanda, "Broad-spectrum sun-protective action of 
Porphyra-334 derived fromPorphyra vietnamensis," Pharmacognosy Research, vol. 2, no. 1, pp. 45-49, 2010.

[20] J. Ryu, S.-J. Park, I.-H. Kim, Y. H. Choi, and T.-J. Nam, "Protective effect of porphyra-334 on UVA-induced photoaging in human skin fibroblasts," International Journal of Molecular Medicine, vol. 34, no. 3, pp. 796-803, 2014.

[21] S.-S. Suh, S. K. Oh, S. G. Lee, I.-C. Kim, and S. Kim, "Porphyra-334, a mycosporine-like amino acid, attenuates UVinduced apoptosis in HaCaT cells," Acta Pharmaceutica, vol. 67, no. 2, pp. 257-264, 2017.

[22] J. Ryu, M.-J. Kwon, and T.-J. Nam, "Nrf2 and NF- $\kappa$ B signaling pathways contribute to porphyra-334-mediated inhibition of UVA-induced inflammation in skin fibroblasts," Marine Drugs, vol. 13, no. 8, pp. 4721-4732, 2015.

[23] S.-S. Suh, S. Lee, U. Youn, S. Han, I.-C. Kim, and S. Kim, "Comprehensive expression profiling and functional network analysis of porphyra-334, one mycosporine-like amino acid (MAA), in human keratinocyte exposed with UV-radiation," Marine Drugs, vol. 15, no. 7, p. 196, 2017.

[24] J. Yoo, J. Kim, J. H. Lee et al., “Acceleration of somatic cell reprogramming into the induced pluripotent stem cell using a mycosporine-like amino acid, Porphyra 334," Scientific Reports, vol. 10, no. 1, p. 3684, 2020.

[25] R. Schmieder and R. Edwards, "Quality control and preprocessing of metagenomic datasets," Bioinformatics, vol. 27, no. 6, pp. 863-864, 2011.

[26] J. Wang, S. Vasaikar, Z. Shi, M. Greer, and B. Zhang, "WebGestalt 2017: a more comprehensive, powerful, flexible and interactive gene set enrichment analysis toolkit," Nucleic Acids Research, vol. 45, no. W1, pp. W130-W137, 2017.

[27] X. Pan, Z. Chen, R. Huang, Y. Yao, and G. Ma, “Transforming growth factor $\beta 1$ induces the expression of collagen type I by DNA methylation in cardiac fibroblasts," PLoS One, vol. 8, no. 4, Article ID e60335, 2013.

[28] M. Hashem, K. Y. Jun, E. Lee, S. Lim, H. Y. Choo, and Y. Kwon, "A rapid and sensitive screening system for human type I collagen with the aim of discovering potent anti-aging or anti-fibrotic compounds," Molecules and Cells, vol. 26, no. 6, pp. 625-630, 2008.

[29] D. S. Yoo, S. J. Jang, Y. J. Park, S. H. Kim, and H.-S. Hwang, "Antiaging effects of musa sapientum L. (Banana) leaf extract," Korean Society for Biotechnology and Bioengineering Journal, vol. 31, no. 2, pp. 126-134, 2016.

[30] L. D. Muiznieks and F. W. Keeley, "Molecular assembly and mechanical properties of the extracellular matrix: a fibrous protein perspective," Biochimica et Biophysica Acta (BBA)Molecular Basis of Disease, vol. 1832, no. 7, pp. 866-875, 2013.

[31] G. A. Di Lullo, S. M. Sweeney, J. Körkkö, L. Ala-Kokko, and J. D. San Antonio, "Mapping the ligand-binding sites and disease-associated mutations on the most abundant protein in the human, type I collagen," Journal of Biological Chemistry, vol. 277, no. 6, pp. 4223-4231, 2002.

[32] W. K. Cho, H.-I. Kim, S.-Y. Kim et al., "Anti-aging effects of Leontopodium alpinum (Edelweiss) callus culture extract through transcriptome profiling," Genes, vol. 11, no. 2, p. 230, 2020.

[33] L. Olvan, T. Fleck, and V. L. Vega, "Global periorbital skin rejuvenation by a topical eye cream containing low molecular weight heparan sulfate (LMW-HS) and a blend of naturally derived extracts," Journal of Cosmetic Dermatology, vol. 18, pp. 530-538, 2019.

[34] G. Cauffman, I. Liebaers, A. Van Steirteghem, and H. Van de Velde, "POU5F1 isoforms show different expression patterns in human embryonic stem cells and preimplantation embryos," Stem Cells, vol. 24, no. 12, pp. 2685-2691, 2006.

[35] I. S. Yang, H. Son, S. Kim, and S. Kim, "ISOexpresso: a webbased platform for isoform-level expression analysis in human cancer," BMC Genomics, vol. 17, p. 631, 2016.

[36] P. M. Gehrig, C. You, J. H. Kägi et al., "Electrospray ionization mass spectrometry of zinc, cadmium, and copper metallothioneins: evidence for metal-binding cooperativity," Protein Science, vol. 9, pp. 395-402, 2000.

[37] N. Sakulsak, "Metallothionein: an overview on its metal homeostatic regulation in mammals," International Journal of Morphology, vol. 30, no. 3, pp. 1007-1012, 2012.

[38] B. Ruttkay-Nedecky, L. Nejdl, J. Gumulec et al., "The role of metallothionein in oxidative stress," International Journal of Molecular Sciences, vol. 14, no. 3, pp. 6044-6066, 2013.

[39] M. Valko, M. Izakovic, M. Mazur, C. J. Rhodes, and J. Telser, "Role of oxygen radicals in DNA damage and cancer incidence," Molecular and Cellular Biochemistry, vol. 266, no. 1/2, pp. 37-56, 2004.

[40] P. Pacher, J. S. Beckman, and L. Liaudet, "Nitric oxide and peroxynitrite in health and disease," Physiological Reviews, vol. 87, no. 1, pp. 315-424, 2007.

[41] B. Halliwell and J. M. C. Gutteridge, "Oxygen free radicals and iron in relation to biology and medicine: some problems and concepts," Archives of Biochemistry and Biophysics, vol. 246, no. 2, pp. 501-514, 1986.

[42] P. J. Thornalley and M. Vašák, "Possible role for metallothionein in protection against radiation-induced oxidative stress. Kinetics and mechanism of its reaction with superoxide and hydroxyl radicals," Biochimica et Biophysica Acta (BBA)Protein Structure and Molecular Enzymology, vol. 827, no. 1, pp. 36-44, 1985.

[43] J. Abel and N. Deruiter, "Inhibition of hydroxyl-radicalgenerated DNA degradation by metallothionein," Toxicology Letters, vol. 47, no. 2, pp. 191-196, 1989.

[44] M. Dutsch-Wicherek, J. Sikora, and R. Tomaszewska, "The possible biological role of metallothionein in apoptosis," Frontiers in Bioscience, vol. 13, pp. 4029-4038, 2008.

[45] M. Si and J. Lang, "The roles of metallothioneins in carcinogenesis," Journal of Pediatric Hematology/Oncology, vol. 11, p. 107, 2018.

[46] D. C. Altieri, "Survivin and apoptosis control," Advances in Cancer Research, vol. 88, pp. 31-52, 2003.

[47] N. V. Botchkareva, M. Kahn, G. Ahluwalia, and D. Shander, "Survivin in the human hair follicle," Journal of Investigative Dermatology, vol. 127, no. 2, pp. 479-482, 2007.

[48] M. H. Aziz, A. S. Ghotra, Y. Shukla, and N. Ahmad, "Ultraviolet-B radiation causes an upregulation of survivin in human keratinocytes and mouse skin," Photochemistry and Photobiology, vol. 80, pp. 602-608, 2004.

[49] H. Shen, H. Cheng, H. Chen, and J. Zhang, "Identification of key genes induced by platelet-rich plasma in human dermal papilla cells using bioinformatics methods," Molecular Medicine Reports, vol. 15, no. 1, pp. 81-88, 2017.

[50] A. Shen, L. Liu, H. Chen et al., "Cell division cycle associated 5 promotes colorectal cancer progression by activating the ERK signaling pathway," Oncogenesis, vol. 8, pp. 1-12, 2019.

[51] S. K. Deshmukh, A. P. Singh, and S. Singh, "ETV4: an emerging target in pancreatic cancer," Oncoscience, vol. 5, no. 9-10, p. 260, 2018.

[52] X. F. Zhu, M. Yi, J. He et al., "Pathological significance of MAD2L1 in breast cancer: an immunohistochemical study and meta analysis," International Journal of Clinical and Experimental Pathology, vol. 10, no. 9, p. 9190, 2017. 
[53] N. Halberg, C. A. Sengelaub, K. Navrazhina, H. Molina, K. Uryu, and S. F. Tavazoie, "PITPNC1 recruits RAB1B to the Golgi network to drive malignant secretion," Cancer Cell, vol. 29, no. 3, pp. 339-353, 2016.

[54] M. Milstein, C. K. Mooser, H. Hu et al., "RIN1 is a breast tumor suppressor gene," Cancer Research, vol. 67, no. 24, pp. 11510-11516, 2007.

[55] S. J. Field, F.-Y. Tsai, F. Kuo et al., "E2F-1 functions in mice to promote apoptosis and suppress proliferation," Cell, vol. 85, no. 4, pp. 549-561, 1996.

[56] G. Zhang, P. He, J. Gaedcke et al., "FOXL1, a novel candidate tumor suppressor, inhibits tumor aggressiveness and predicts outcome in human pancreatic cancer," Cancer Research, vol. 73, no. 17, pp. 5416-5425, 2013.

[57] Y. Yamagishi, T. Sakuno, Y. Goto, and Y. Watanabe, "Kinetochore composition and its function: lessons from yeasts," FEMS Microbiology Reviews, vol. 38, no. 2, pp. 185-200, 2014.

[58] R. C. Allshire and G. H. Karpen, "Epigenetic regulation of centromeric chromatin: old dogs, new tricks?" Nature Reviews Genetics, vol. 9, no. 12, pp. 923-937, 2008.

[59] A. B. Jaffe and A. Hall, "Rho gtpases: biochemistry and biology," Annual Review of Cell and Developmental Biology, vol. 21, no. 1, pp. 247-269, 2005.

[60] M. Mori, K. Saito, and Y. Ohta, "ARHGAP22 localizes at endosomes and regulates actin cytoskeleton," PLoS One, vol. 9, no. 6, Article ID e100271, 2014.

[61] M. A. Moreno-Mateos, Á. G. Espina, B. Torres et al., "PTTG1/ securin modulates microtubule nucleation and cell migration," Molecular Biology of the Cell, vol. 22, no. 22, pp. 4302-4311, 2011.

[62] C. A. Dinarello, "Interleukin-1, interleukin-1 receptors and interleukin-1 receptor antagonist," International Reviews of Immunology, vol. 16, no. 5-6, pp. 457-499, 1998.

[63] O. Beaslas, J. Metso, E. Nissilä et al., "Osbpl8 deficiency in mouse causes an elevation of high-density lipoproteins and gender-specific alterations of lipid metabolism," PLoS One, vol. 8, Article ID e58856, 2013.

[64] M. Yasunaga and Y. Matsumura, "Role of SLC6A6 in promoting the survival and multidrug resistance of colorectal cancer," Scientific Reports, vol. 4, p. 4852, 2014.

[65] L. Samuelov, E. Sprecher, D. Tsuruta, T. Bíró, J. E. Kloepper, and R. Paus, "P-cadherin regulates human hair growth and cycling via canonical Wnt signaling and transforming growth factor- $\beta 2$," Journal of Investigative Dermatology, vol. 132, no. 10, pp. 2332-2341, 2012.

[66] P. Nigam, "Desmogleins: hair perspective," International Journal of Trichology, vol. 5, no. 1, p. 2, 2013.

[67] Y. Hanakawa, H. Li, C. Lin, J. R. Stanley, and G. Cotsarelis, "Desmogleins 1 and 3 in the companion layer anchor mouse anagen hair to the follicle," Journal of Investigative Dermatology, vol. 123, no. 5, pp. 817-822, 2004. 